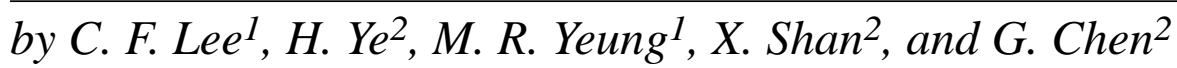

\title{
AIGIS-based methodology for natural terrain landslide susceptibility mapping in Hong Kong
}

\author{
1 Department of Civil Engineering, The University of Hong Kong, Pokfulam Road, Hong Kong, China; Fax number: +852-2559-5337; E-mail: \\ leecf@hku.hk
}

2 Institute of Geology, China Seismological Bureau, P.O.Box 9803, Beijing 100029, China

\begin{abstract}
This paper presents a novel application of Artificial Intelligence (AI) and Geographic Information System (GIS) to the mapping of natural terrain landslide susceptibility in Hong Kong. The method is applied to the central part of Lantau Island as a pilot study. First, we discuss the key technical concepts of AI and GIS, the advantages of their integrated application, and the growing importance of remote sensing data. We then describe the working procedure including the construction of the GIS database, pre-treatment of input data, and training of the network classifier. High prediction rates and positive outcomes from reliability tests demonstrate the success of the methodology and show its great potential for use in landslide disaster mitigation planning in Hong Kong.
\end{abstract}

\section{Introduction}

Hong Kong has suffered severely from landslide disasters. Natural slopes in Hong Kong are commonly steep. More than $60 \%$ of the land area is steeper than $15^{\circ}$, and about $40 \%$ is steeper than $30^{\circ}$. Hong Kong has a subtropical monsoon climate with a mean annual rainfall of about 2,200 $\mathrm{mm}$. About $80 \%$ of the rain falls between May and September, with daily rainfall that can be over $300 \mathrm{~mm}$ (Au, 1995, 1998, Evans, 1996, 1997). The combination of the hilly terrain, high seasonal rainfall and high density of the urban environment gives rise to severe landslide problems in Hong Kong. Landslides have caused serious casualties and property loss in the past and are a significant public concern.

Since the early 1970s, much work on slope stability evaluation has been done by the Geotechnical Engineering Office (GEO) and other professionals in Hong Kong (Lumb, 1975 and Brand, 1989). Past efforts on slope stabilization in Hong Kong are mainly focused on man-made slopes. Recently, however, because of rapid urban expansion, the stability of natural slopes has become a subject of increasing importance in Hong Kong. Landslides on natural terrain can develop into large mobile flows. Such flows may cause significant damage to urban areas adjacent to steep slopes. Due to the quick pace of urban development in Hong Kong, decisions need to be made by the city authority regarding existing and proposed development in areas that are exposed to landslides originating from natural slopes.

The work described in this paper is aimed at developing a new method for identifying areas of the natural terrain in Hong Kong that are susceptible to landslides. New techniques of Artificial Intelligence (AI) and Geographic Information System (GIS) are applied to achieve a highly computerized, efficient and objective system. We hope that the methodological framework presented in this paper can be used to compile an AIGIS-based natural terrain landslide susceptibility map that would provide valuable new information for landslide hazard assessment and disaster mitigation planning in Hong Kong.

The central part of Lantau Island with an area of approximately $45 \mathrm{~km}^{2}$ has been selected as the pilot study area for this work (Figure 1 ). The area is covered by four 1:5,000-scale topographic maps: designated 9-SE-B, 9-SE-D, 10-SW-A, and 10-SW-C. Located in the southwestern part of the Territory, Lantau Island is the largest outlying island and the target of future economic development in Hong Kong. The topography of the pilot study area ranges from flat to precipitous (GCO, 1988, Wong et al., 1996). The area starts with a narrow coastal plain in the north, and then rises southward rapidly over undulating footslope terrain to the northeast-to-east trending central range of Lantau Island, with the highest elevation reaching about $860 \mathrm{~m}$. The topographic complexity makes it a suitable test area for the present study.

The work is based on a comprehensive collection and analysis of data on landslides and relevant factors. Most of the data used in this study are provided by relevant authorized agencies, e.g. GEO, the Land Information Centre (LIC), and the Hong Kong Observatory (HKO). The work is carried out in close cooperation with GEO.

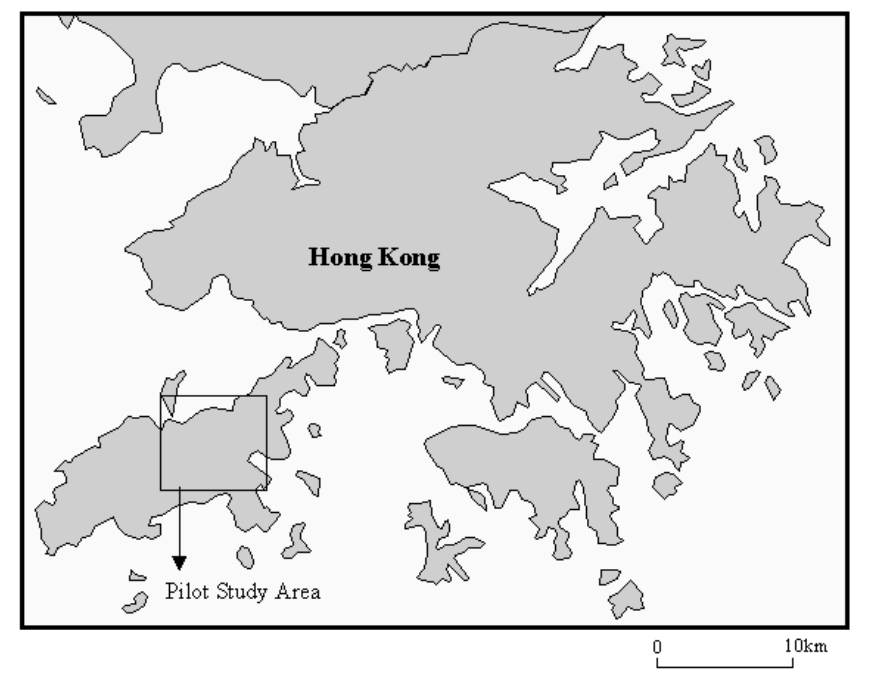

Figure 1 Map showing the location of the pilot study area.

\section{Technical approach}

\section{Overview}

The most challenging part of the regional landslide susceptibility assessment is to evaluate slopes in places where landslides have not yet taken place. The work is based on a commonly accepted hypothesis that the main conditions that cause landslides in a particular region are controlled by a set of environmental factors related to 
regional geology, geomorphology, topography, vegetation, climate, etc. With the appropriate regional environmental data and analytical tools, these landslide-causative conditions in a region are, in principle, identifiable. Therefore, they can be used as the basis for assessing landslide susceptibility in places currently free of landslides.

Over the past two decades, different kinds of methods (Hutchinson, 1995; Einstein, 1997), varying from deterministic to purely statistical or a combined approach (combination of statistical calculation with professional judgement based on experience) have been proposed as analytical tools for dealing with this problem. A common limitation of all these methods is that it is difficult to objectively handle the non-linear multivariate property of the problem. It is well recognized that the various environmental factors causing landslide in a region are rather complexly interrelated (Jade and Sarkar, 1993). For example, slope instability may be related to slope angle in very different ways for different geologic or geomorphologic units. Moreover, the relationships are highly non-linear in nature. Conventional statistical models (multiple regression and discriminant function techniques, etc.) are primarily designed to deal with linear problems. Therefore, they are inappropriate for assessing complex non-linear problems. One way to improve the poor performance of conventional statistical models in landslide susceptibility assessment is to incorporate some kind of physical analysis or judgement into the model with a hybrid methodology. But this would increase subjectivity and indefiniteness. Clearly, to overcome this dilemma we need more powerful mathematical tools that are capable of dealing with non-linear problems and, at the same time, minimising subjectivity.

\section{Artificial Intelligence}

Researchers in AI, a field of computer science, attempts to use a computer system to model human cognitive processes. A welldeveloped technique in AI called Artificial Neural Network (ANN) is selected for this work as the mathematical tool to replace the conventional ones.

ANN is a sophisticated form of non-linear pattern recognition that mimics some of the intellectual actions of human brains. The main features of ANN include large-scale parallel distributed processing, continuous non-linear dynamics, collective computation, high fault-tolerance, self-organization, self-learning, and real-time treatment (Rumelhart and McClelland, 1986).

A schematic diagram of an ANN is shown in Figure 2. An ANN is composed of neurons and synapses. A neuron is a node or computational element in the network. It uses a transfer function to convert an input value to an output value. Neurons are connected by synapses. A synapsis takes the output value from one neuron and multiplies it by a weight, then passes the modified signal to an adjacent neuron as input. The synaptic weights are variables that could be dynamically adjusted in computing to fit the training samples. Neurons are usually structured in the form of a sequence of layers connected by synapses between successive layers. For each neural net, there are two layers serving as buffers: an input layer which takes data into the network and an output layer which holds the output of the network from a given set of input. Layers between the input and output layers are called hidden layers.

One of the most successful and popular ANN techniques, the back-propagation (BP) network, is employed in this work. A typical BP network has an input layer, an output layer, and at least one hidden layer. Each layer in the BP network is fully connected to the succeeding layer. The net connectivity and neuron transfer function are held constant. The behaviour of the BP network is trained by adjusting synaptic weights. Initial synaptic weights are assigned from a random distribution. Error signals are computed from the difference between the network's output results and the desired output results (training data). Through an iterative procedure of back-propagation of errors, the synaptic weights between layers are automatically modified to reduce the output error and the network is trained to properly classify the training data. Once the network is trained suc-

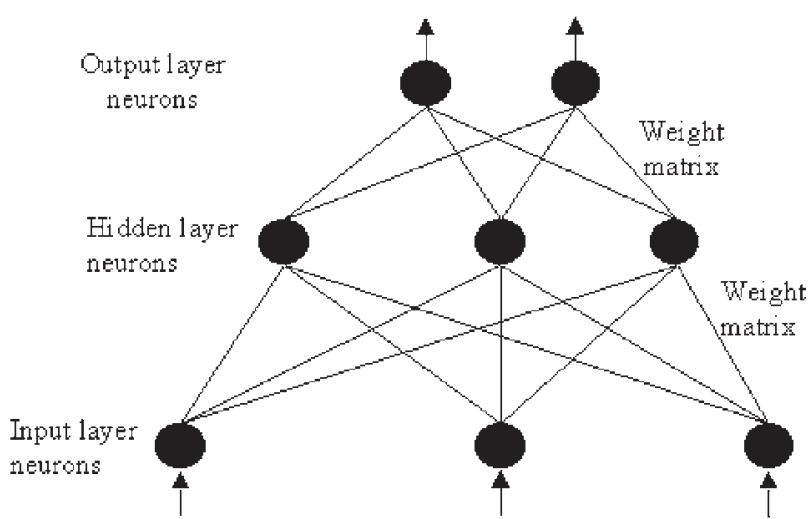

Figure 2 Configuration of Artifical Neural Network.

cessfully, it can be used as a non-linear classifier to classify data samples with unknown classifications. follows:

The input into each neuron in the BP network is processed as

$$
x_{j}^{(s)}=f\left(\sum_{i} w_{j i}(s) * x_{j}^{(s-1)}=f\left(I_{j}^{(s)}\right)\right.
$$

where $x_{j}(s)$ is the current output of the $j$-th neuron in layer $S ; w_{j i}(s)$ is the weight for synapsis joining the $i$-th neuron in layer (S-1) to the $j$ th neuron in layer $\mathrm{S} ; I_{j}(s)$ is the weighted summation of input to the $j$ th neuron in layer $\mathrm{S}$; and $f$ is a transfer function. The dynamic modification of the synaptic weight $w_{j i}(s)$ is based on the Delta Rule which minimizes the global error $\mathrm{E}$ through changing synaptic weights according to the gradient descent rule. The incremental modification of a synaptic weight is computed as

$$
\Delta w_{j i}(s)=-l c o e f * e_{j}^{(s)} * x_{i}^{(s-1)}
$$

where $e_{j}^{(s)}$ is a learning coefficient; and lcoef is a measure of local error at processing the $j$-th neuron in layer $\mathrm{S}$.

It is through this dynamic modification of a large number of synaptic weights that a BP network derives much of its cognitive power. Any BP network with one or more hidden layers using a nonlinear neuron transfer function is capable of solving complex nonlinear problems (Eberhart and Dobbins, 1990; Paola and Schowengerdt, 1995).

\section{Combination of AI and GIS}

A modern GIS is a computer system designed to store, manage, synthesize, analyse, display and update geographically associated information. The geographic referencing of the information permits the data sets to be linked spatially. This provides a powerful tool for processing and integration of large amounts of data from many different sources in their spatial context (Borcherdt, 1995 and Ye et al., 1997). GIS significantly facilitates the manipulation of spatial data, enables spatial analysis capabilities, and enhances the visualization of analytical processes and results. The procedure of landslide susceptibility assessment usually has to deal with rather complex multidisciplinary spatial databases and requires intensive processing and integration of the spatial information. Thus, the consensus is that landslide susceptibility assessment is preferably conducted on a GIS software platform.

A distinct feature of the present work is to implement an ANN system on a GIS platform. The integrated system analyses data extracted from the GIS and returns results to the GIS. In this way, the large amount of spatial data analysed by the ANN learning machine and the results produced can be manipulated fully with the capabilities of the GIS technology. This further extends the functionality of the ANN and, at the same time, increases the set of possible applications of GIS. The major advantages of using AIGIS-based methodology for landslide susceptibility assessment are as follows: 
1. An AIGIS-based system has the ability to objectively explore the non-linear relationship between landslide susceptibility and relevant environmental factors which conventional methods are unable to resolve properly.

2. It accepts different types of mathematical parameters (e.g. class, ordinal, continuous and boolean) as input or output values. Therefore, it is well suited for consolidating all multidisciplinary landslide-related factors, which are usually of different mathematical types, into a single model.

3. The pre-treatment and normalization of the input data and the display or query of the results are all conveniently performed on a GIS platform. All the spatial data can be easily edited, converted, rescaled, re-projected and overlaid for a visual or quantitative comparison.

4. The system is extremely flexible, capable of incorporating any improved new data set. As new information is entered, the final results are automatically updated.

5. It is suitable for integrating ground surface information with remote sensing data, which is of great importance in the present work.

\section{Utilisation of remote sensing data}

Many researchers have noted that remote sensing data are increasingly important in the assessment of landslide susceptibility. Another important feature of the present work is that nearly all the advanced techniques for remote sensing data processing have been embedded into the AIGIS system. The system developed by this work has the capability to fully manipulate various kinds of remote sensing data. Satellite images are integrated with ground surface data and extensively used in the work, first to be interpreted for the identification or revision of surface factors (e.g. vegetation, structural lineament, etc.), then to be put into the ANN classifier as background training data. By fusing different remote sensing data sets of the same area and merging satellite images with ground surface data, a variety of new information can be extracted. This proves to be very useful in producing high-resolution surface data for the pilot study area.

\section{Construction of primary GIS database}

\section{Software platform and data sources}

The GIS software platform selected for this study is MapInfo Professional 5.0. It works in the Windows 98 environment. Programming languages MapBasic 4.0, Visual Basic and Visual $\mathrm{C}$ are used to develop application models and customize the user interface. The state-of-the-art EASI/PACE image processing package from PCI 6.2 is integrated with the MapInfo software for processing the satellite images.

The Landslide Susceptibility Assessment (LSA) GIS database in the present work is established with data from the following sources:

1. 1:20,000-scale Natural Terrain Landslide Inventory (NTLI) maps and special project report compiled by GEO, Hong Kong.

2. 1:5,000-scale topographic maps compiled by LIC, Hong Kong.

3. 1:20,000-scale solid and superficial geologic maps with accompanying memoirs compiled by GEO, Hong Kong.

4. Geotechnical Area Studies Programme (GASP) reports and associated 1:20,000-scale terrain classification maps compiled by GEO, Hong Kong.

5. Average rainfall data issued by $\mathrm{HKO}$.

6. Satellite images from the U.S. LANDSAT Thematic Mapper (TM), French SPOT High Resolution Visible (HRV), and India's IRS-1C.

The primary LSA GIS database of the present study consists of a suite of map-layers derived from the data. Each map-layer is recorded as various map elements and associated attributes. The MapInfo GIS data management system supports both vector and raster formats. Map elements representing spatial information are stored either in vector or raster format. A vector map-element and its associated attribute data are stored in the same file. The geometric accuracy of a GIS map-layer is controlled by the scale of its source map.

\section{Landslide distribution map-layer}

The Hong Kong 1:20,000-scale NTLI maps are compiled based on the interpretation of high level aerial photographs taken from altitudes of over 3,000 $\mathrm{m}$ in the years 1945,1964 and each of 1972 to 1994 except 1977 (Evans et al., 1997). The features recorded in the inventory include both fresh scars of landslides that occurred during, or shortly before, the period covered by the aerial photography (1945 to 1994), and overgrown scars originally formed by earlier landslides. These two types of features are referred to as recent and relict landslides, respectively, on NTLI maps. On the grounds of year of first observation, it can be stated approximately that all the relict landslides occurred before 1972 and nearly all the recent landslides occurred after 1943. Relict and recent landslides on NTLI maps are digitised and entered separately into the LSA GIS as two vector map-layers. In the pilot study area, the relict landslide map-layer contains a total of 661 landslides, and the recent landslide map-layer contains a total of 559 landslides (Figure 3).

\section{Primary topography map-layer}

The LIC 1:5,000-scale topography maps are used as the geographic base map for the present study. Five selected feature types extracted from 1:5,000-scale topographic maps, coastline, elevation contours, streams, major roads and water ponds, are digitised separately and stored into the LSA GIS as 5 independent vector map-layers. Two of them, the 5-m contour and drainage system map-layers, are further used to create topography-related input maps.

\section{Primary geology map-layer}

The Hong Kong 1:20,000-scale solid and superficial geologic maps are digitised and input to the LSA GIS to create geology-related map-layers. In the pilot study area, there are 24 lithological groups, each comprising geologic units with broadly similar lithology. Referring to the nomenclature of the Hong Kong Geological Survey, these groups are classified into 5 categories (Table 1). For the convenience of visual and quantitative comparison with the landslide distribution, the distribution of each lithological group is digitised and stored as an individual vector map-layer in the LSA GIS. Figure 4 shows a lithological map composed of all lithological vector maplayers. Structural information derived from the digitisation of geologic maps is stored in the fault map-layer and structural lineament map-layer. The latter was further revised based on the interpretation of subsequent remote sensing data.

\section{Primary geomorphology map-layer}

The geomorphology of the pilot study area reflects the complex Quaternary history of climate change and sea level fluctuations in the region. Physical constraints related to the geomorphologic development of the area (Table 2) are extracted from the terrain classification maps associated with the GASP reports. The distribution of each geomorphology-related physical constraint is digitised and stored as an individual vector map-layer. The geomorphologic map composed of geomorphology-related vector map-layers is shown in Figure 5.

\section{Primary erosion map-layer}

The erosion classification of the surface is also derived from the terrain classification maps associated with the GASP reports in which erosion conditions are classified into several classes (Table 3 ). The 
Table 1 Lithological groups in pilot study area.

\begin{tabular}{|c|c|c|}
\hline Category & Symbol & Description \\
\hline \multirow[t]{7}{*}{ Superficial Deposits } & Qa & Alluvium: silt, sand and gravel \\
\hline & Qi & Estuarine deposits: mud and sand \\
\hline & $Q b$ & Beach deposits: sand \\
\hline & Qrb & Back beach deposits: sand \\
\hline & Qd & $\begin{array}{l}\text { Slope debris: sand, gravel, cobbles and boulders } \\
\left(Q_{3}+Q_{4}\right)\end{array}$ \\
\hline & Qpa & Terraced alluvium: silt, sand and gravel \\
\hline & Qpd & Slope debris: sand, gravel, cobbles and boulders $\left(Q_{3}\right)$ \\
\hline \multirow[t]{8}{*}{ Volcanic Rocks } & J1t & Rhyolite lava tuff \\
\hline & Mjlt & Metamorphosed rhyolite lava and tuff \\
\hline & Jsp & Lapilli-bearing crystal tuff \\
\hline & M & Mud \\
\hline & $\mathrm{T}$ & Crystal tuff \\
\hline & $\mathrm{Tt}$ & Tuff and tuffite \\
\hline & $\mathrm{Rh}$ & Rhyolite lava \\
\hline & $\mathrm{E}$ & Eutaxite \\
\hline \multirow[t]{2}{*}{ Sedimentary Rocks } & S1 & Siltstone \\
\hline & S & Sandstone \\
\hline \multirow{4}{*}{$\begin{array}{c}\text { Major Intrusive Igneous } \\
\text { Rocks }\end{array}$} & Gf & Fine-grained granite, $<2 \mathrm{~mm}$ \\
\hline & Gfm & Fine-to medium-grained granite \\
\hline & Gm & Medium-grained granite, $2-6 \mathrm{~mm}$ \\
\hline & Sqf & Fine-grained quartz syenite, $<2 \mathrm{~mm}$ \\
\hline \multirow{3}{*}{$\begin{array}{c}\text { Minor Intrusive Igneous } \\
\text { Rocks }\end{array}$} & B & Basalt \\
\hline & Rf & Feldsparphyric rhyolite \\
\hline & $A p$ & Aplite \\
\hline
\end{tabular}

Table 2 Geomorphologic classes in pilot study area.

\begin{tabular}{|c|l|}
\hline Symbol & \multicolumn{1}{|c|}{ Description } \\
\hline Col & Colluvium \\
\hline CW & Colluvium zone subject to overland flow and periodic zone inundation \\
\hline Fpl & Floodplain subject to overland flow and regular inundation \\
\hline IC & Zones of general instability with predominantly colluvial terrain \\
\hline II & Zones of general instability with predominantly insitu terrain \\
\hline Slo & Slopes on insitu terrain which are steeper than $30^{\circ}$ \\
\hline DT & Disturbed terrain \\
\hline Gul & Gully with moderate or severe erosion \\
\hline Lit & Littoral zone \\
\hline Ot & Others \\
\hline
\end{tabular}

Table 3 Erosion classes in pilot study area.

\begin{tabular}{|c|l|}
\hline Symbol & \\
\hline Rel & General instability (relict) \\
\hline Rec & General instability (recent) \\
\hline Gul & Gully erosion \\
\hline Noe & No appreciable erosion \\
\hline She & Sheet erosion \\
\hline
\end{tabular}

distribution of each erosion class is digitised separately and, similar to the lithological and geomorphologic factors, stored as an individual vector map-layer.

\section{Primary vegetation map-layer}

In the GASP reports, a broad classification system is used to distinguish the types of vegetation on the surface. In the present work, the vegetation class map-layers are created mainly through the interpretation of remote sensing data with the classification categories adopted from the GASP reports (Table 4). The vegetation maps of the GASP are also referred to during the classification process.

\section{Table 4 Vegetation classes in pilot study area.}

\begin{tabular}{|c|l|}
\hline Symbol & \multicolumn{1}{|c|}{ Description } \\
\hline Brd & Mixed broadleaf woodland \\
\hline $\mathrm{Cul}$ & Cultivation \\
\hline $\mathrm{G}$ & Grassland \\
\hline Nov & No vegetation on natural terrain \\
\hline $\mathrm{R}$ & No vegetation on rock outcrops \\
\hline Shg & shrubland $(>50 \%$ canopy cover $)$ \\
\hline Shl & shrubland $(<50 \%$ canopy cover $)$ \\
\hline
\end{tabular}

\section{Primary mean annual rainfall map-layer}

The mean annual rainfall data used in this work is obtained from Lee and Kwan (1984). The 30-year mean annual rainfall isopleth map of the pilot study area for 1953 to 1982 is digitised and input into the LSA GIS forming a vector map-layer. It is used as the basis for examining relationships between landslide occurrence and mean annual rainfall. It should be pointed out that the 30 -year time period does not cover the whole temporal distribution of the landslides studied in this work. However, this set of rainfall data is the best available at present. Besides, it is noted that the isopleths of 30-year mean annual rainfall show a good correlation with the general trend of the relief, implying that the 30 -year records probably reflect a rather long-term rainfall pattern. Thus, for the time being, it is considered as an approximate representation of the mean annual rainfall pattern for the study area.

\section{Primary satellite image map-layer}

The raw satellite images used in this work include those from the U.S. LANDSAT TM, French SPOT HRV and India's IRS-1C. They are all transformed from digital sources into the LSA GIS system. Details of the above data are listed in Table 5. The raw satellite images are registered to a map-layer with root-mean-square (RMS) errors for registration and rectification of less than 1 pixel. Atmosphere correction and geometric correction are conducted for all raw satellite images before any further processing. Processing is conducted using PCI's EASI/PACE image processing package.

Table 5 Details of satellite images used in the work.

\begin{tabular}{|c|c|c|c|}
\hline & LANDSAT TM & SPOT HRV & IRS-1C \\
\hline $\begin{array}{c}\text { Number of spectral } \\
\text { band }\end{array}$ & 7 & 3 & Panchromatic \\
\hline Scan width & $150 \mathrm{~km}$ & $60 \mathrm{~km}$ & $70 \mathrm{~km}$ \\
\hline Spatial resolution & $30 \mathrm{~m}$ & $20 \mathrm{~m}$ & $5.8 \mathrm{~m}$ \\
\hline Spectral range & $\begin{array}{c}0.45-2.35 \mu \mathrm{m} \\
10.40-12.5 \mu \mathrm{m}\end{array}$ & $0.50-0.89 \mu \mathrm{m}$ & $0.5-0.75 \mu \mathrm{m}$ \\
\hline Revisit time & 16 days & $2-26$ days & $5-24$ days \\
\hline Acquisition Date & 1996.3 & 1997.1 & 1997.5 \\
\hline
\end{tabular}




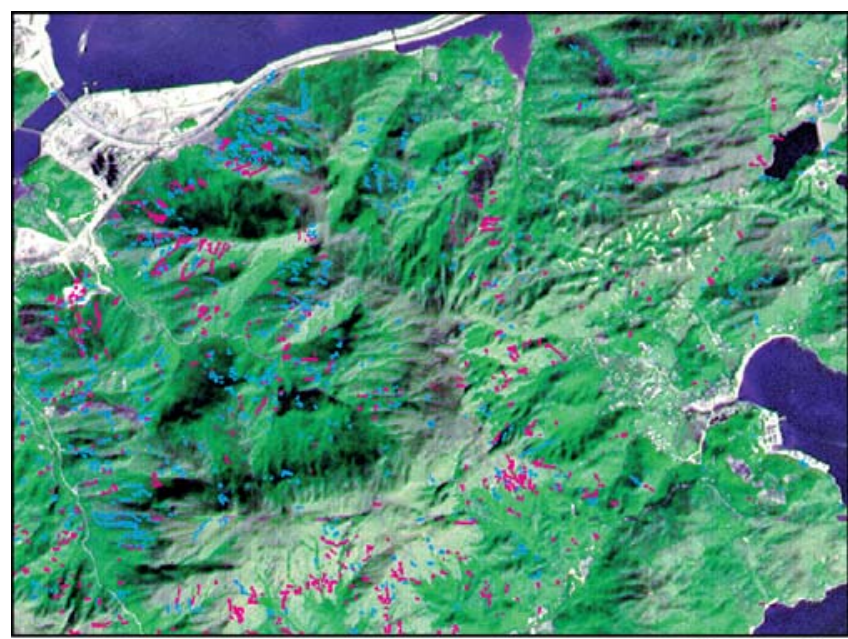

- Relict Landslides Recent Landslides $800 \mathrm{~m}$

Figure 3 Natural terrain landslides in the pilot study area.

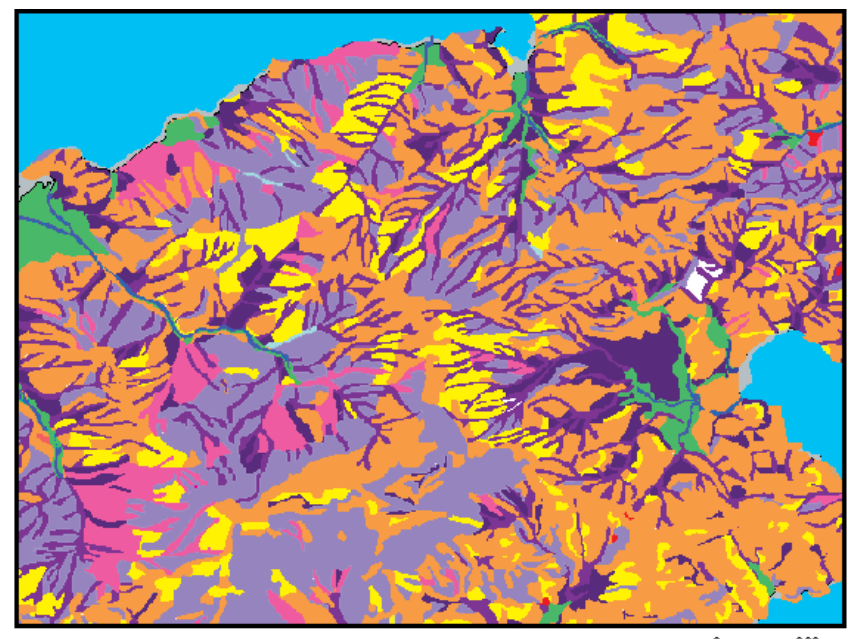

$\begin{array}{llllllllll}\square & \square & \square & \square & \square & \square & \square & \square & \square & \square \\ \text { Col } & \square & \text { II } & \text { Slo } & \text { DT } & \text { Gul } & \text { Lit } & \text { Ot }\end{array}$

Figure 5 Geomorphologic map of the pilot study area.

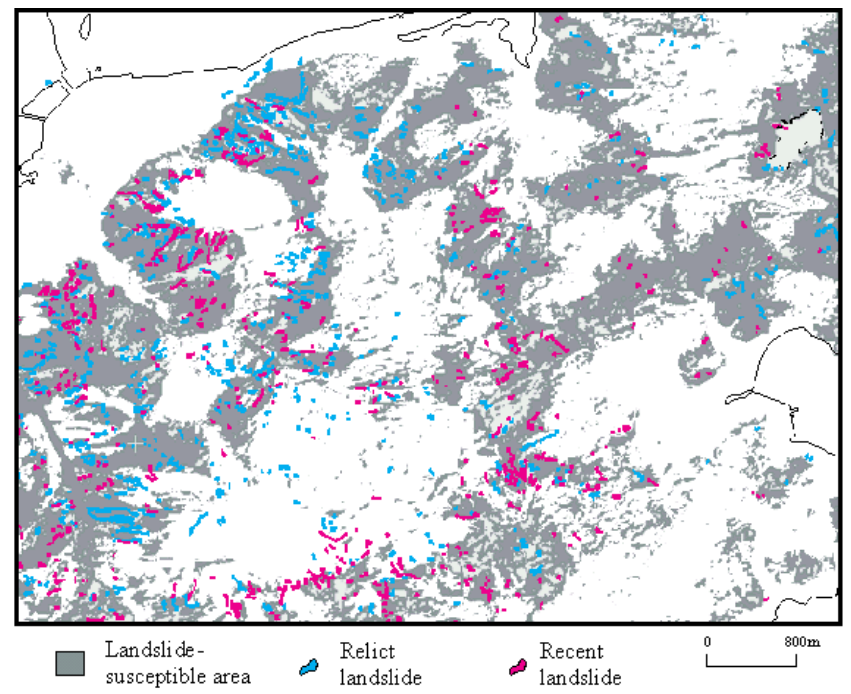

Figure 20 Result of AIGIS based landslide susceptibility assessment.
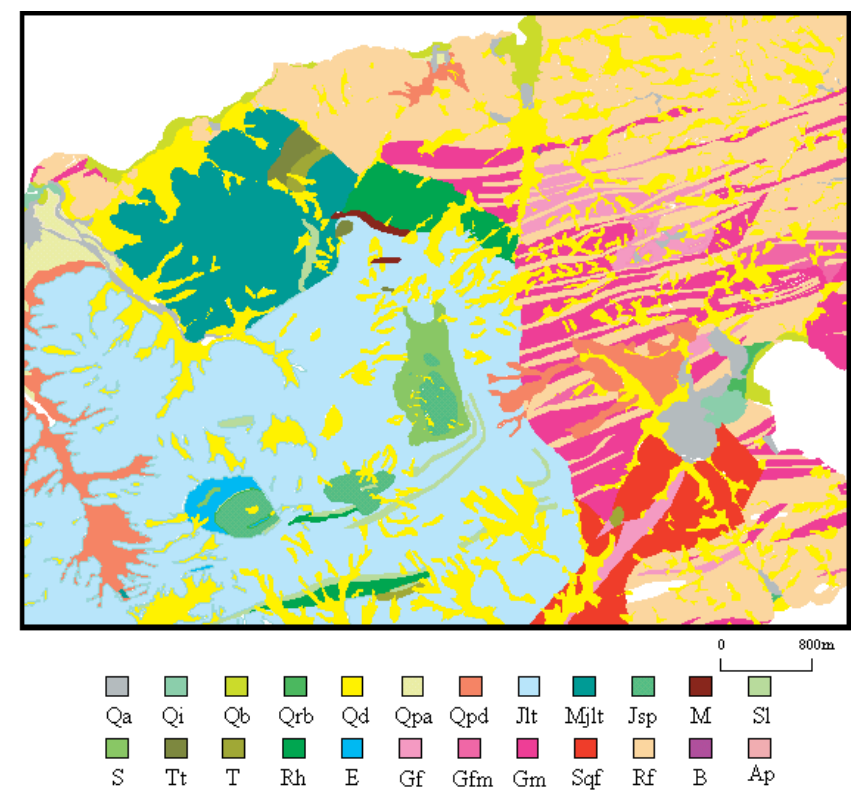

Figure 4 Lithological map of the pilot study area.

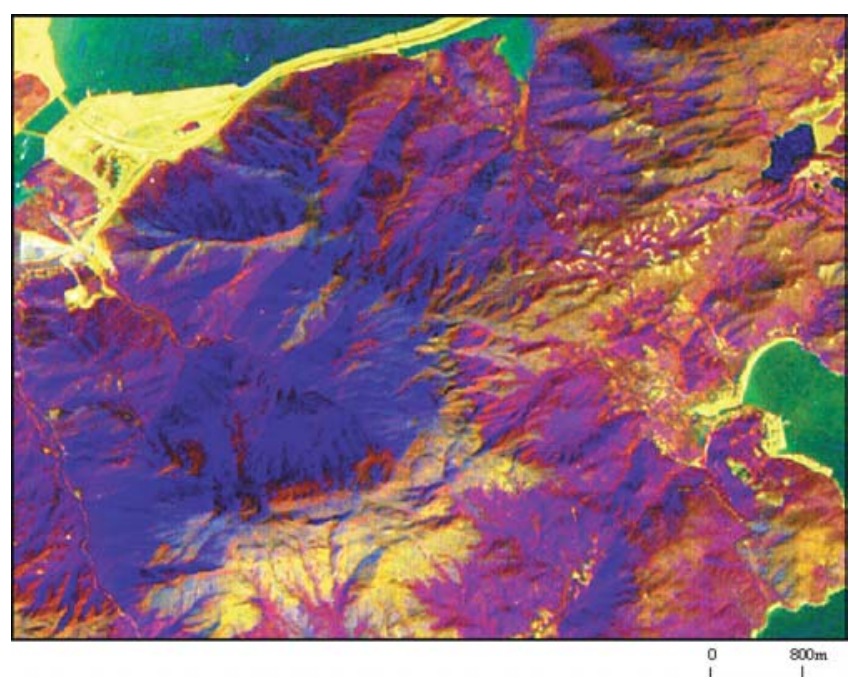

Figure 19 Satellite image input map.

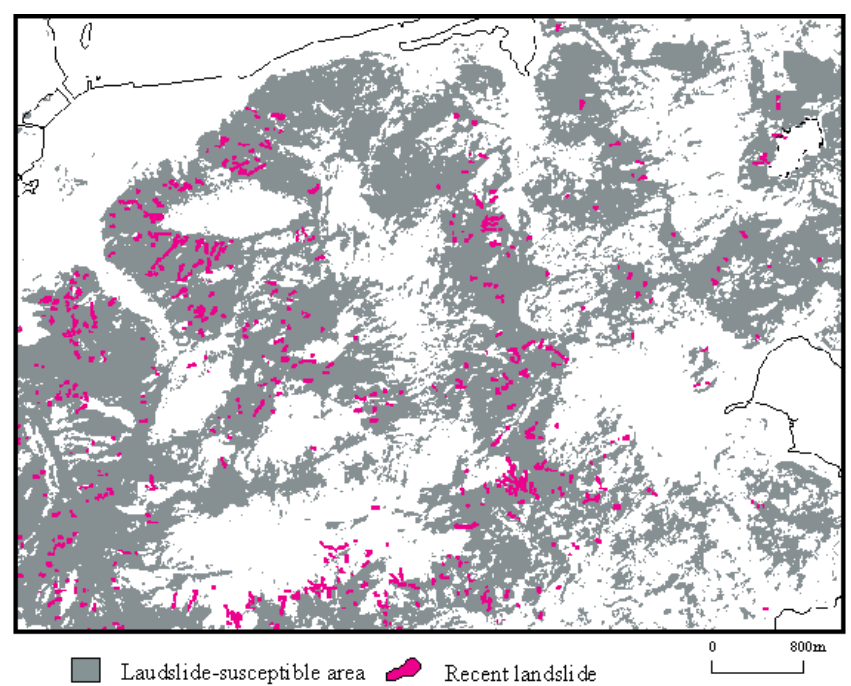

Figure 21 Result of reliability test. 


\section{Pre-treatment and normalisation of input data}

Input data need to be normalised before being imported into the BP network. Once the primary GIS map-layers are prepared, the next step is to create a series of secondary map-layers through a normalisation process. The landslide density, defined as the ratio of landslide area to total area, is adopted as the normalisation parameter. All the primary vector map-layers described in the previous sections are converted into the raster format through a vector-raster conversion procedure provided by MapInfo Professional 5.0. Considering the geometric resolution of the SPOT HRV and IRS-1C fused satellite images, the pixel dimension is designed to be $5.8 \mathrm{~m}$. The normalised grey level of each map-element is assigned based on the landslide density of the element. In other words, in these secondary map-layers of information we use the spatial variation of grey level to delineate landslide density distribution pattern related to a specific environmental factor. Through this data pre-treatment and normalisation process 10 secondary map-layers are prepared as the input maps for the BP network: lithology input map (Figure 6), geomorphology input map (Figure 8), erosion input map (Figure 10), vegetation input map (Figure 13), mean annual rainfall input map (Figure 14), fault and lineament input map (Figure 15), drainage input map (Figure 16), digital elevation model input map (Figure 17), slope angle input map (Figure 18), and satellite image input map (Figure 19).

The lithology input map is created from the primary lithology vector map-layers described previously. As mentioned before, in the pilot study area there are 24 lithological groups classified into 5 categories (Table 1). The average landslide density of each of these 24 lithology groups is shown in Figure 7. It can be seen from Figure 7 that areas underlain by tuff, tuffite, lava and siltstone are marked by relatively high landslide densities. In contrast, most of the areas covered by superficial deposits (except debris flows) or underlain by minor intrusive igneous rocks have very low or zero landslide densities. The distinct contrast between the groups with high landslide density and those with low landslide density indicates that lithology has a significant influence on the occurrence of landslides. The lithology input map composed of various map-elements of different grey levels (Figure 6) comprises all the normalized local landslide density information related to the underlain lithological property. Thus, it can be used as lithology-related input for the BP network. By using the spatial analysis functionality of GIS, the process of data pre-treatment and normalization is conducted efficiently and conveniently on the present AIGIS software platform.

The geomorphology input map (Figure 8), erosion input map (Figure 10), vegetation input map (Figure 13), mean annual rainfall input map (Figure 14) fault and lineament input map (Figure 15) and drainage input map (Figure 16) are all created through similar processes as those for the lithology input map. To calculate the landslide density in the vicinity of a linear map-element (e.g. a fault, lineament or stream), the buffer technique of GIS is used. The distributions of landslide density for different classes of some of these environmental factors are shown in Figures 9, 11 and 12. It appears that, to a greater or lesser extent, all the environmental factors considered display correlation with landslide susceptibility and therefore are appropriate input data for the BP network classifier training.

The digital elevation model (DEM) input map (Figure 17) and slope angle input map (Figure 18) are created on the basis of the 5$\mathrm{m}$ contour vector map-layer. Between them, the DEM input map, which is a mathematical representation of relief in terms of $x, y$ and $z$ coordinates, is the fundamental one. Through a vector-raster conversion process, the DEM input map is directly created by the interpolation of the contour lines. Slope angle input map is subsequently created by the DEM numerical modelling capability.

To enhance the satellite image input map, centre-weighted filtering and linear contrast stretch are performed to optimise the quality of SPOT HRV and IRS-1C images. Then, the improved images are fused through an Intensity-Hue-Saturation (IHS) transformation.
The resulting image (Figure 19) contains information from both SPOT HRV and IRS-1C. It has a high geometric resolution similar to that from IRS-1C and, at the same time, retains the multispectral information from SPOT HRV (Table 5).

\section{ANN classification}

\section{Network training}

A state-of-the-art BP neural network classifier software developed recently by PCI is chosen for the present study. This software offers a supervised learning approach to neural network classification working in raster format.

As described previously, a neural network consists of three types of neurons: input, output and hidden neurons. The known landslides including both relict and recent landslides derived from the NTLI are used as training samples. Altogether 1,220 landslides are used as training samples in this study. Each of the ten normalized input maps described previously is used as training data and imported to an input neuron. Based on empirical experience, 12 hidden neurons are used in the neural network. When presented with the set of training data, the non-linear relationships between the input data and the desired output pattern can be obtained by the self-adaptive learning of the network through an iterative process. Once the network is trained to the point where the RMS errors of the output is below an acceptable level, it is regarded as an adequate classifier and is used to identify areas susceptible to landslides.

\section{Results and reliability tests}

The trained network is used to classify the landslide-susceptible portion of the pilot study area. The results of the classification are shown in Figure 20. It can be seen from Figure 20 that the areas recognized to have landslide-prone characteristics include some areas where no landslides have been recorded in the NTLI. It means that the methodology used in this study not only identifies dangerous areas near the sites of landslides used as training samples but also predicts potential landslides distant from these known landslides. This is exactly the aim of the present study.

To investigate the reliability of the developed classifier, a crossvalidation study is performed to test the predictive ability of the classifier. The idea is that, when learning is based only on part of the known landslides, we may test the algorithm's predictive ability by computing the prediction rate of the remaining known landslides. Since our questions are not time dependent, it makes no difference what part of the landslide inventory we use as training data in performing the test. But for the sake of logic, we choose the relict landslides as the training data to predict the recent landslides registered in the NTLI. The results of the cross-validation study are shown in Figure 21 . Nearly $85 \%$ of the recent landslides are predicted by the $\mathrm{BP}$ classifier. This verifies the reliability of the classifier.

Another measure taken to examine the reliability of the developed classifier is to use the classifier to predict landslides occurring after 1994 that are not included in the NTLI. A study of GEO's latest landslide database reveals that approximately $90 \%$ of the landslides occurring between 1995 and 1998 are located in the landslide-susceptible areas delineated by the present study (personal communication with GEO expert P. Kirk). This further confirms the reliability of the present methodology.

\section{Discussion and conclusions}

\section{Usage and limitations}

It should be pointed out that susceptibility mapping is only part of a complete hazard assessment, although it is a very important part and usually the first step in a complete hazard assessment. The objective 


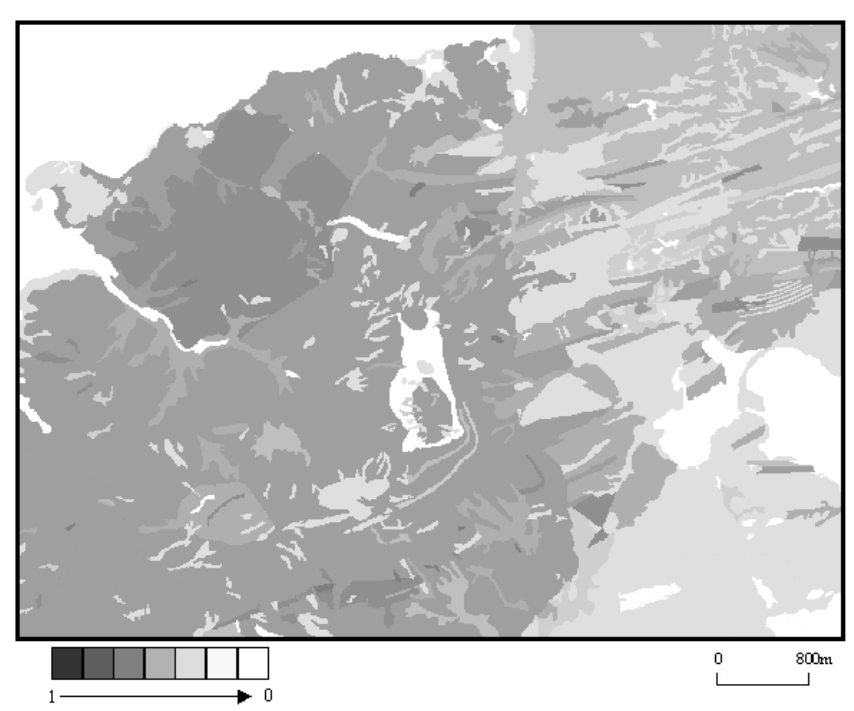

Figure 6 Lithology input map.

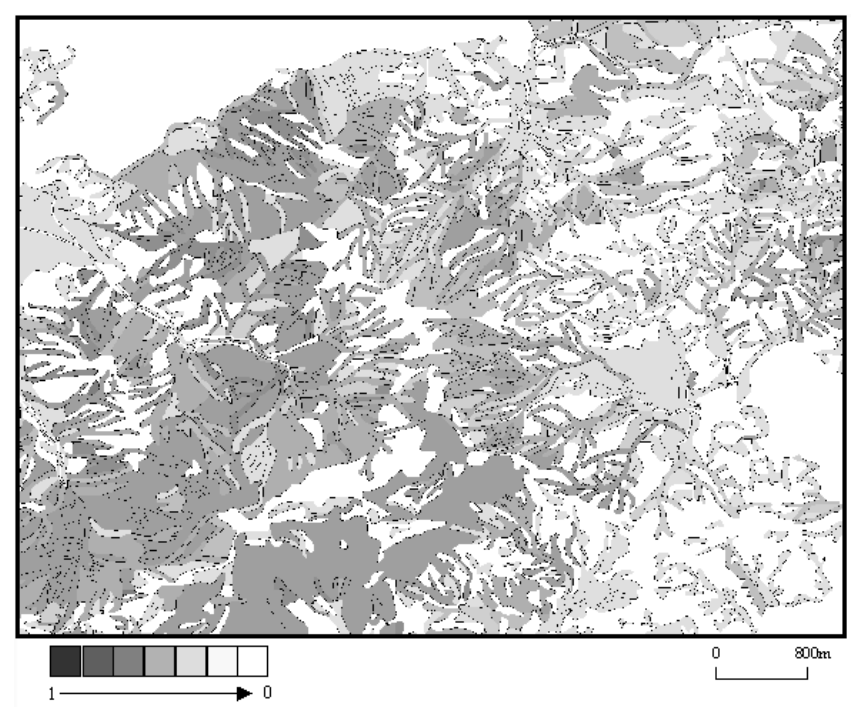

Figure 8 Geomorphology input map.

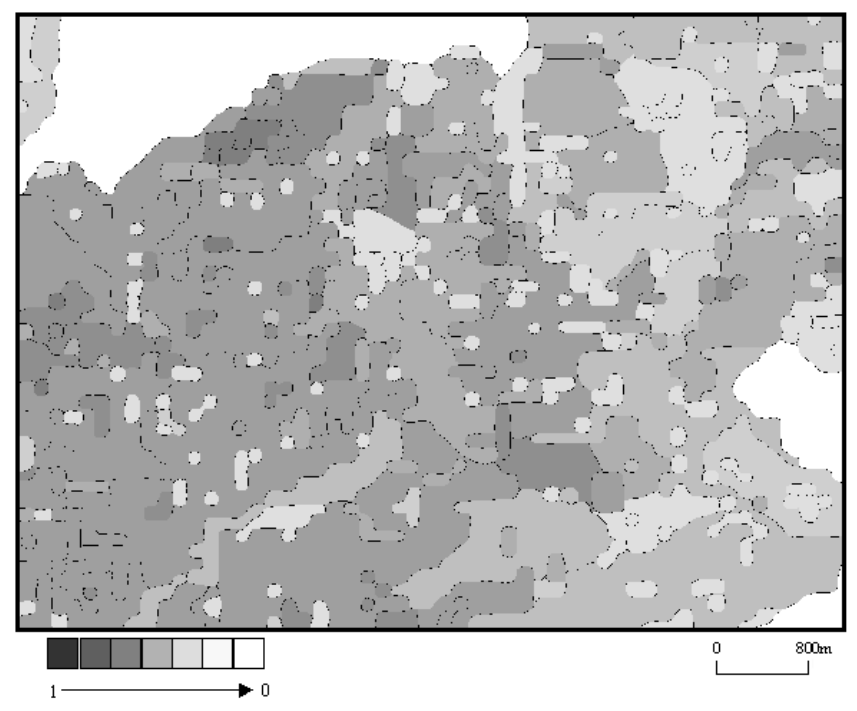

Figure 10 Erosion input map.

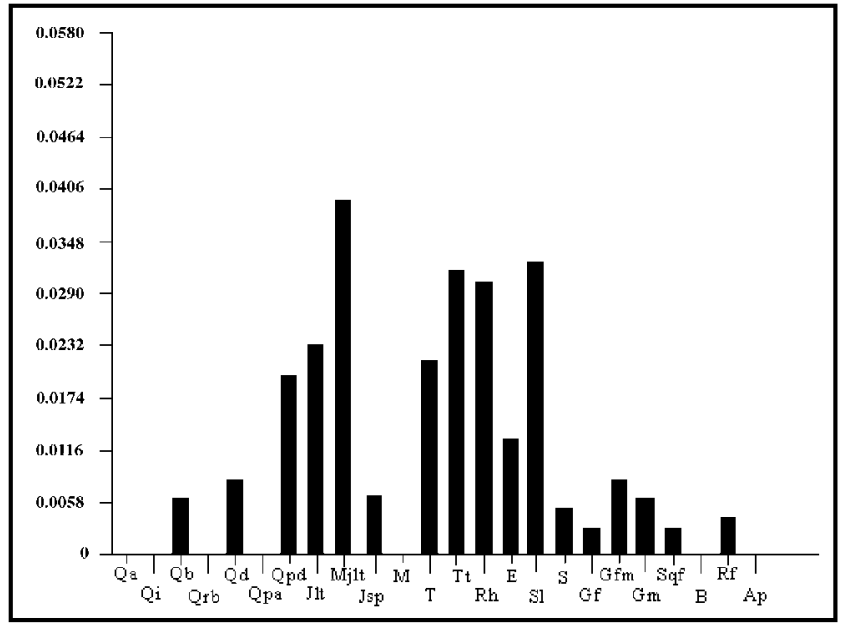

Figure 7 Landslide density of lithological groups.

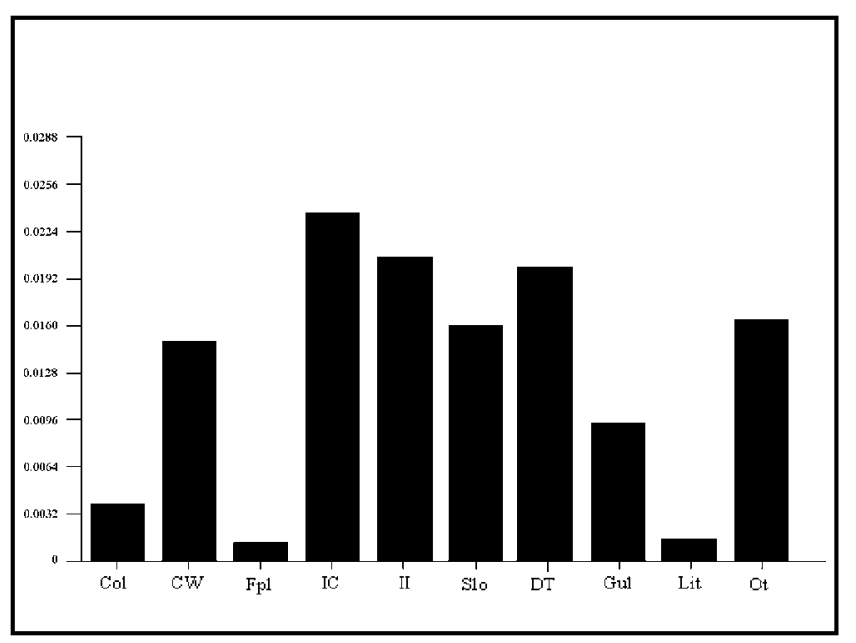

Figure 9 Landslide density of geomorphologic groups.

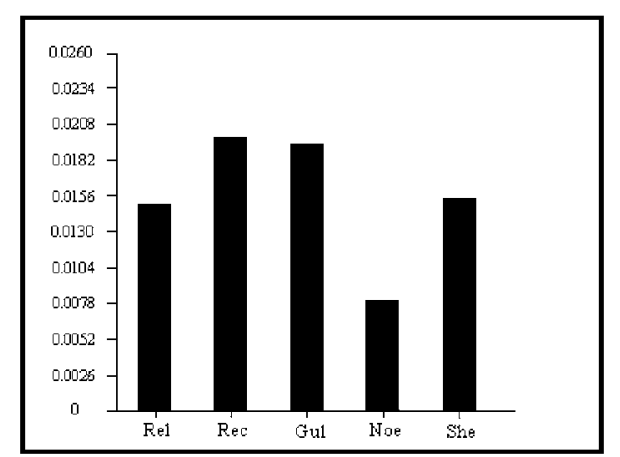

Figure 11 Landslide density of erosion classes.

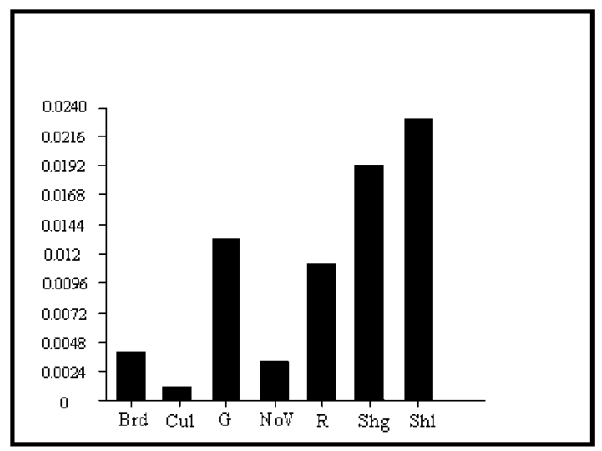

Figure 12 Landslide density of vegetation classes. 


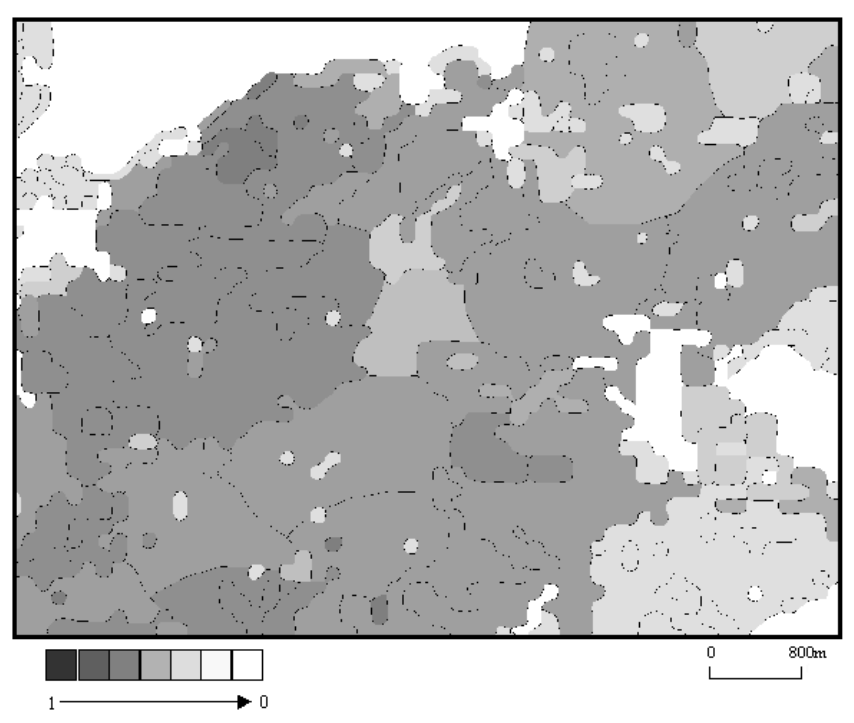

Figure 13 Vegetation input map.

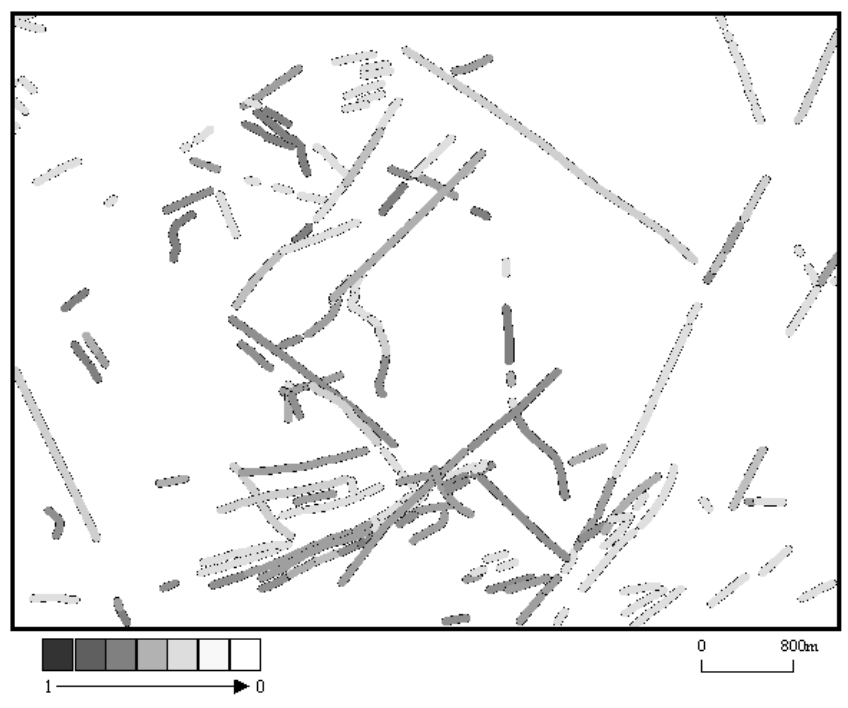

Figure 15 Fault and lineament input map.

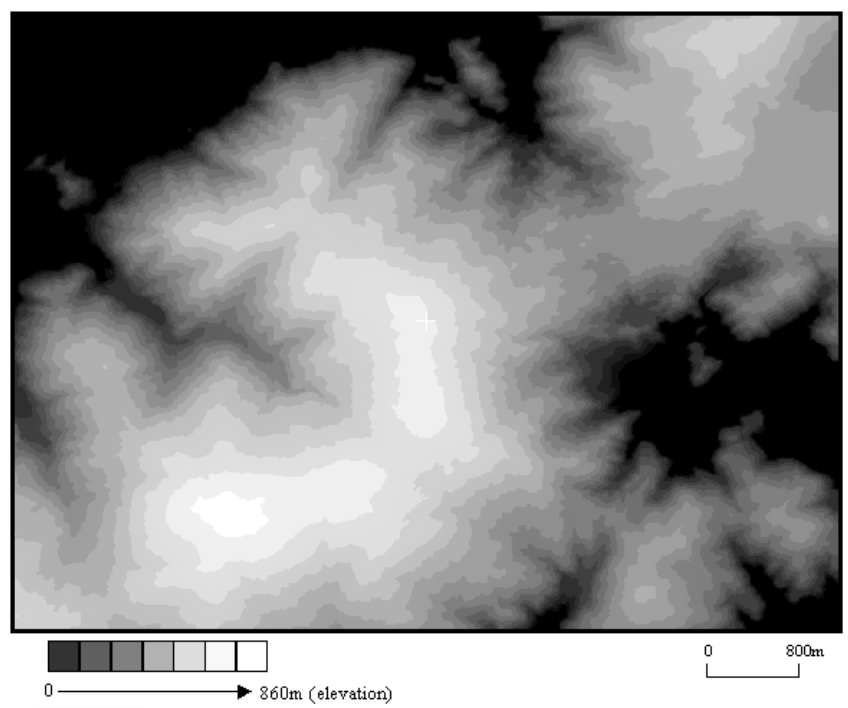

Figure 17 Digital elevation model input map.

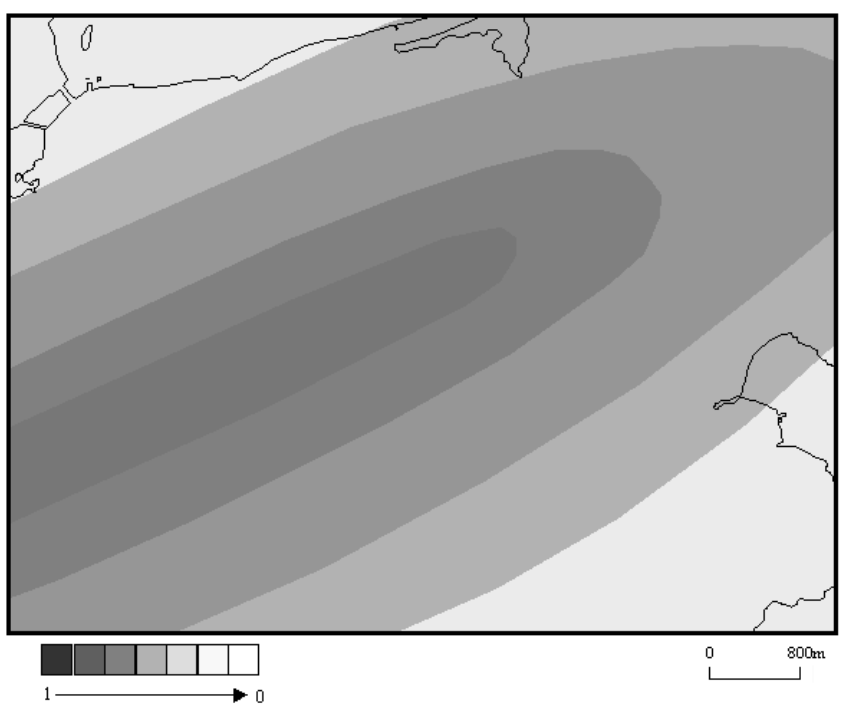

Figure 14 Mean annual rainfall input map.

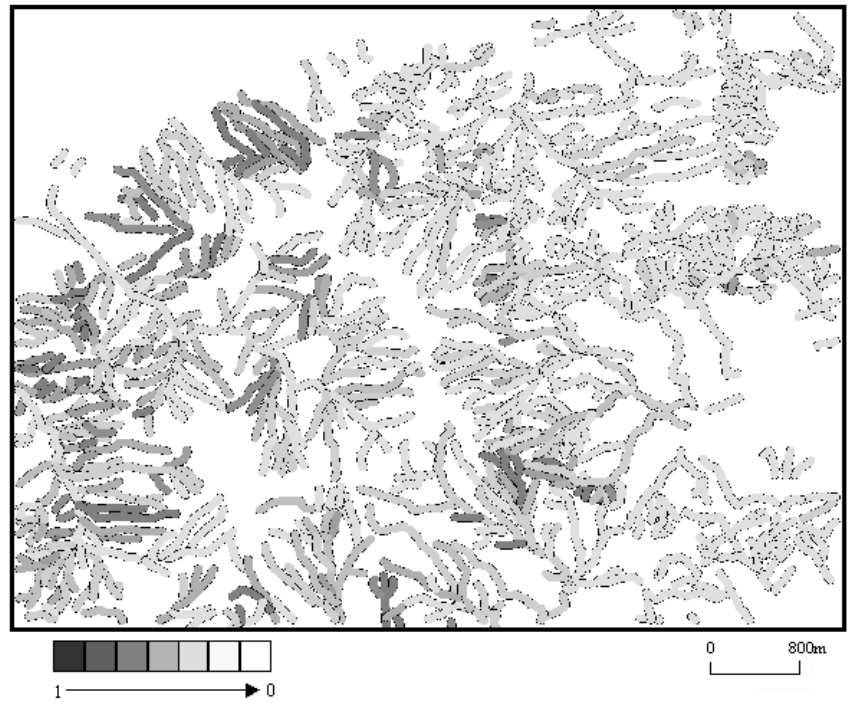

Figure 16 Drainage input map.

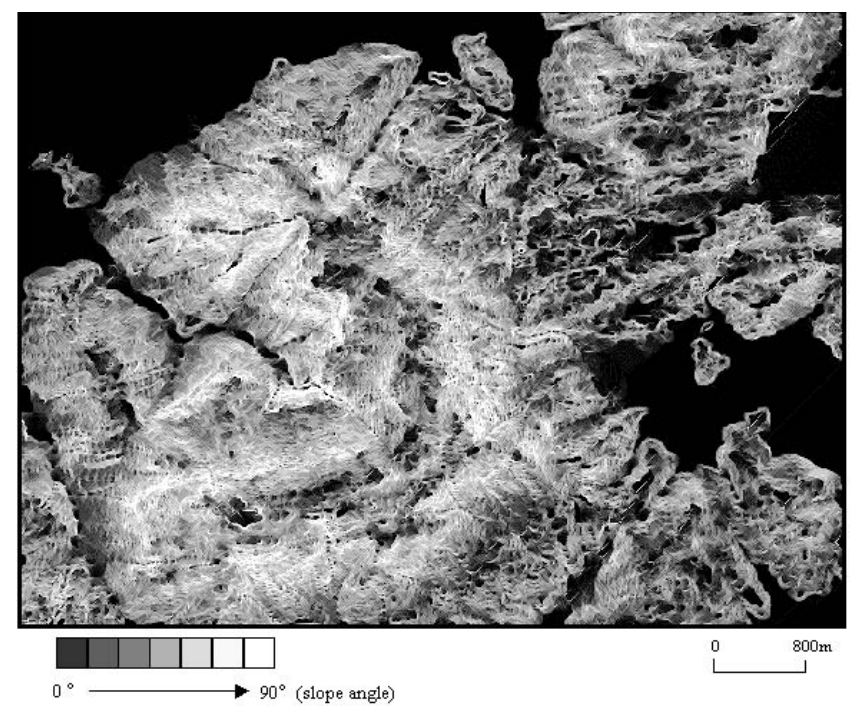

Figure 18 Slope angle input map. 
of landslide susceptibility mapping is to identify areas susceptible to the initiation of landslides. In contrast, a qualified assessment of landslide hazard has to give the probability of landslide occurrence within a specified time period in a given area or at a specific site and its natural consequence as well. This involves both spatial and temporal analysis of landslide distribution and also requires the evaluation of probable severity and impact of landslide events such as probable size, runout distance and the speed of mobilized debris, etc. However, similar to the role of potential seismic sources in seismic hazard assessment (Shah et al., 1991), the landslide-prone areas delineated by landslide susceptibility mapping form the most important basis for the assessment of landslide hazard. The demand for land in Hong Kong leads to a continuing trend of urban expansion close to steep natural slopes. The susceptibility mapping performed by the present study may serve as the first step toward the mitigation of natural terrain landslide disasters in Hong Kong. Based on this fundamental work, a more sophisticated hazard assessment should be conducted.

\section{Uncertainties and further improvement}

In general, a susceptibility assessment involves three kinds of uncertainties: natural uncertainties, parameter uncertainties and model uncertainties. Natural uncertainties due to the stochastic variation of various types of natural conditions are, in principle, not reducible. Parameter uncertainties related to data limitation (e.g. quality, quantity, biases, etc.) and model uncertainties caused by simplification or imperfection of the analytical tools are the main targets of further improvement.

For the present study, although extensive data collection is conducted to ensure the maximum use of available data, detailed data on some factors are still lacking, especially those on the Quaternary geology and geomorphologic features. It is possible that in the near future, more advanced remote sensing data of superficial geology and geomorphologic features in Hong Kong will be available. With an improved training data set it is expected that uncertainties involved in the present model can be reduced and the prediction rate can be raised further.

\section{Concluding remarks}

1. The results of the present study indicate that the ANN has the capability of properly dealing with complex non-linear relationships between landslide occurrence and various environmental factors. Thus it proves to be an ideal mathematical tool for regional landslide susceptibility mapping.

2. Assessment of landslide susceptibility is greatly facilitated by a GIS. The combination of AI and GIS (AIGIS) allows us to extend the functionality of either technique in many new ways, resulting in a highly computerized, efficient and easy-to-use working system.

3. Remote sensing data have great potential in contributing to landslide susceptibility mapping. The remote sensing processing software embedded in our AIGIS system benefits the work substantially.

4. The usability and advantage of the present methodology are validated convincingly by the cross-validation study and newly registered landslide events. Thus, the methodology deserves further consideration for use in a regional landslide hazard assessment for natural terrain in Hong Kong.

\section{Acknowledgements}

Valuable advice and data support are kindly provided by C.Y. Chan, P. Whiteside, R. Martin, N. Woods, P. Kirk, J. King, S.H. Mak, M.C. Chan, W.K. Pun, C.H. Tan and R. Shaw, all of GEO, Civil Engineering Department, Hong Kong. The authors also gratefully acknowledge K.T. Law, S.J. Wang, C.H. Zhou, X.J. Xue, V. Lam and Z.Q. Yue for their suggestions and consultation during the work.

\section{References}

Au, S. W. C., 1993, Rainfall and slope failure in Hong Kong. Engineering Geology, v. 36, pp. 141-147.

Au, S. W. C., 1998, Rain-induced slope instability in Hong Kong. Engineering Geology, v. 51, pp. 1-36.

Borcherdt, R. D., Lawson, S., Pessina, V., Bouabid , J., and H. Shah, 1995, Applications of Geographic Information System Technology (GIS) to seismic zonation and earthquake loss estimation. in Proceeding of Fifth International Conference on Seismic Zonation. v. 3, pp.1933-1948.

Brand, E. W., 1989, Occurrence and significance of landslides in Southeast Asia. in Brabb \& Harrod, eds, Landslides: Extent and Economic Significance, Balkema, Rotterdam, pp.303-309.

Eberhart, R. C. and Dobbins, R. W., 1990, Neural Network PC Tools. Academic Press, London, 414pp.

Einstein, H. H., 1997, Landslide risk-Systematic approaches to assessment and management. in Cruden \& Fell, eds, Landslide Risk Assessment, Balkema, Rotterdam, pp.25-50.

Evans, N. C., 1996, Natural terrain landslide study: Rainfall distribution and orographic effects in Hong Kong. Geotechnical Engineering Office, Hong Kong, Discussion Note DN 3/96,30pp.

Evans, N. C., 1997, Natural terrain landslide study: Preliminary assessment of the influence of rainfall on natural terrain landslide initiation. Geotechnical Engineering Office, Hong Kong, Discussion Note DN $1 / 97,28 \mathrm{pp}$.

Evans, N. C., Huang, S. W., and King, J. P., 1997, The natural terrain landslide study, phase 1 and phase 2. Geotechnical Engineering Office, Civil Engineering Department, Hong Kong.

Geotechnical Control Office, 1988a, Geotechnical Area Studies Programme-North Lantau. Geotechnical Control Office, Hong Kong, GASP Report no VI, 124pp.

Geotechnical Control Office, 1988,. Geotechnical Area Studies Programme-South Lantau. Geotechnical Control Office, Hong Kong, GASP Report no. VI, 148 pp.

Hutchinson, J. N., 1995, Keynote Paper: Landslide hazard assessment. in Bell (ed), Landslide, Balkema, Rotterdam, pp. 1805-1841.

Jade, S., and Sarkar, S., 1993, Statistical models for slope instability classification. Engineering Geology, v.36 pp.91-98.

Lee, B. Y., and Kwan, W. K., 1984. 30-year mean rainfall in Hong Kong 1953-1982, Technical Note No. 70, Hong Kong Observatory.

Lumb, P., 1975, Slope failures in Hong Kong. Quarterly Journal of Engineering Geology. v.8, pp.31-65.

Paola, J. D., and Schowengerdt, R. A., 1995, A detailed comparison of backpropagation neural network and maximum-likelihood classifiers for urban land use classification. IEEE Transactions on Geoscience and Remote Sensing. v. 33, pp.981-995.

Rumelhart, D. E., and McClelland, J. L., 1986. Parallel Distributed Processing. MIT Press.

Shah, H., Richard B., and Dong, W., 1991. Geographic Information System and Artificial Intelligence: An application for seismic zonation. in Proceeding of Fourth International Conference on Seismic Zonation. v. 1, pp.487-517.

Wong, H. N., Chen, Y.M., \& Lam, K. C., 1996. Factul report on the November 1993 natural terrain landslides in three study areas on Lantau Island. Special Project Report No.SPR10/96, Geotechnical Engineering Office, Hong Kong, v.3, p. 452.

Ye, H., Zhou, Q., Qu, C., and Shan, X., 1997. Application of GIS to seismic hazard analysis in Mainland China, Proceedings of GIS AM/FM ASIA'97 and Geoinformatics' 97. pp.203-211. 
C. F. Lee is presently Chair Professor in Geotechnical Engineering, Department of Civil Engineering, University of Hong Kong. He worked on a variety of power projects for Ontario Hydro, Canada between 1975 and 1993. His current interests include seismic hazard and landslide hazard mitigation.

H. Ye is Director of the Engineering GIS Lab, Institute of Geology, Seismological Bureau of China and Adjunct Professor in the Department of Geology, Peking University. He is currently Depute Secretary-General of the Geological Society of China. His current research interests include application of Artificial Intelligence and GIS in geosciences, seismic hazard and landslide hazard assessment, seismotectonics and crustal stress field.
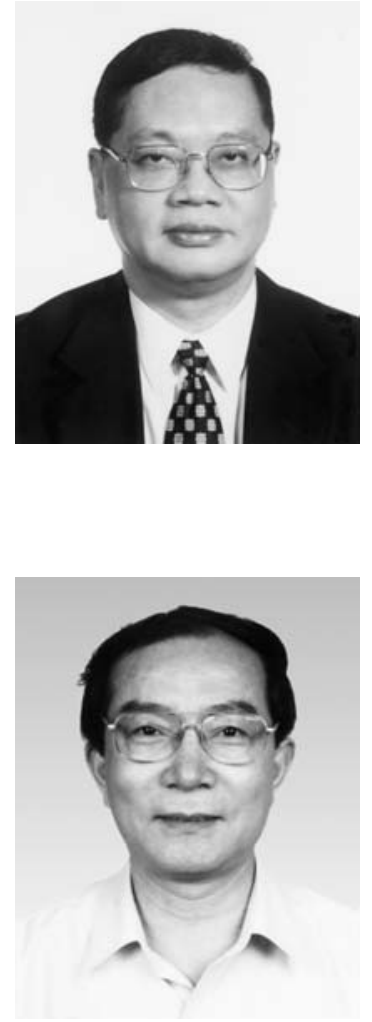

M. R. Yeung is an assistant professor in the Department of Civil Engineering at the University of Hong Kong. He specializes in soil mechanics, rock mechanics, and geological engineering. His research has been aimed at developing methods of analysis and design for discontinuous rock masses. These methods include block theory and the discontinuous deformation analysis (DDA). In addition, he is interested in landslide hazard mitigation and geotechnical earthquake engineering.

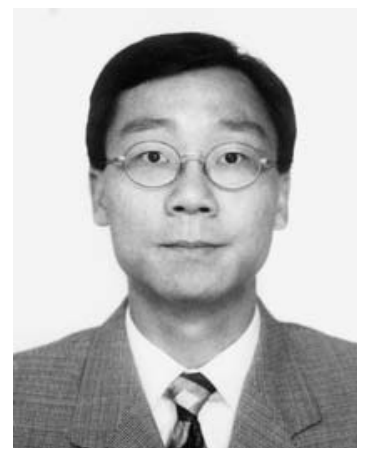

\section{Franz Kossmat Volume Cretaceous Stratigraphy}

An Update

Guest Editor

A. Govindan

Geological Society of India P.B. 1922, Gavipuram

P.O., Bangalore-560 019, India

2000

Paperback, 426pp.

ISBN 81-85867-43-7

Rs $500 / \$ 50$

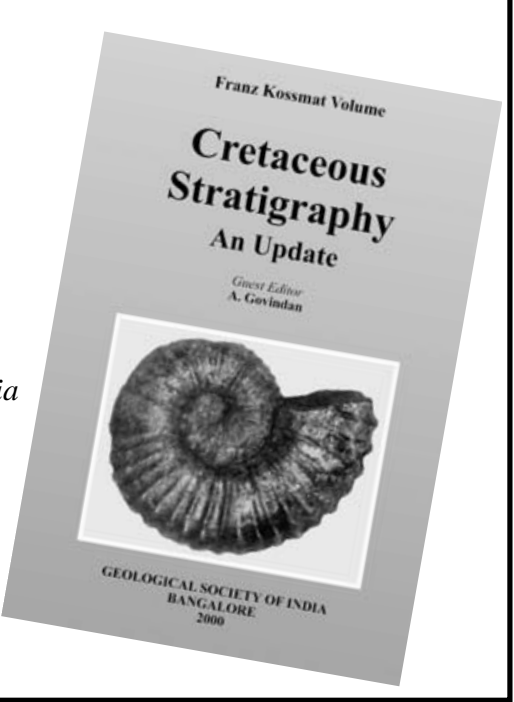

